\section{In vitro fermentation of three species of fresh grass differing in water-soluble carbohydrate content with an equine faecal inoculum}

Jennifer C. Ince', Annette C. Longland', Meriel J. S. Moore-Colyer ${ }^{7}$ and Patricia A. Harris²

Institute of Grassland and Environmental Research, Plas Gogerddan, Aberystwyth $^{1}$ and Equine Studies Group, WALTHAM Centre for Pet Nutrition, Melton Mowbray ${ }^{2}$ twice the rate of $\mathrm{T}\left(0.06973 \mathrm{~h}^{-1}\right.$ compared to $\left.0.03543 \mathrm{~h}^{-1}\right)$. C was intermediate $\left(0.04647 \mathrm{~h}^{-1}\right)$ and significantly faster $(\mathrm{P}<0.05)$ than $\mathrm{T}$. DM loss was significantly greater $(\mathrm{P}<0.05)$ for $P(971 \mathrm{~g} / \mathrm{kg})$ than $C(945 \mathrm{~g} / \mathrm{kg})$ and $T(933 \mathrm{~g} / \mathrm{kg})$, as was the total gas pool accumulated $(252.2 \mathrm{ml}$ for $\mathrm{T}$ compared to $325.3 \mathrm{ml}$ and $359.0 \mathrm{ml}$ for $C$ and $P$ respectively, see Table 1).

Table 1 Water-soluble carbohydrate (WSC) content and fermentation parameters of three species of fresh grass when incubated in vitro with an equine faecal inoculum. * FRGP, fractional rate of gas production.

\begin{tabular}{|l|l|l|l|l|}
\hline Parameter & $\begin{array}{l}\text { Perennial } \\
\text { ryegrass }\end{array}$ & Cocksfoot & Timothy & Sed \\
\hline Total WSC $(\mathrm{g} / \mathrm{kg} \mathrm{DM})$ & 34.85 & 25.83 & 21.54 & - \\
\hline Total Gas pool $(\mathrm{ml})$ & $359.0^{\mathrm{b}}$ & $325.3^{\mathrm{b}}$ & $252.2^{\mathrm{a}}$ & 13.61 \\
\hline FRGP $\left(\mathrm{h}^{-1}\right)^{*}$ & $0.06973^{\mathrm{c}}$ & $0.04647^{\mathrm{b}}$ & $0.03543^{\mathrm{a}}$ & 0.001731 \\
\hline DM loss $(\mathrm{g} / \mathrm{kg})$ & $971^{\mathrm{b}}$ & $945^{\mathrm{a}}$ & $933^{\mathrm{a}}$ & 0.440 \\
\hline
\end{tabular}

* FRGP, fractional rate of gas production

Values across rows not bearing the same superscript differ significantly $(P<0.05)$

\section{Discussion}

\section{Introduction}

Water-soluble carbohydrates (WSC) comprising glucose, sucrose, fructose and fructan are readily fermented by equine hind-gut micro-organisms. The fructan fraction of WSC is poorly degraded by mammalian enzymes (Nilsson et al. 1988) and therefore passes relatively undigested into the hind-gut where it is rapidly fermented. This rapid fermentation can produce an overgrowth of lactate producing bacteria which, in turn, may result in hindgut acidosis. Temperate pasture grasses can accumulate high concentrations $(>300 \mathrm{~g} / \mathrm{kg}$ dry matter) of fructan, the amounts varying with plant species and environmental conditions. It is therefore possible that horses grazing such pasture may ingest potentially dangerous amounts of fructan (Longland and Cairns 2001). Whilst the effects of varying amounts of WSC in dried, ground grass on fermentation kinetics have been studied in vitro (Longland and Murray 2003), there is no published work to date using fresh grass. In order to better emulate grazing conditions, this study sought to determine the rate and extent of fermentation by an equine hindgut microbial inoculum of three species of fresh grass was investigated in vitro.

\section{Materials and methods}

Fresh grasses (equivalent of $1 \mathrm{~g}$ dry matter [DM]) Timothy (T), Cocksfoot $(\mathrm{C})$ and Perennial ryegrass $(\mathrm{P})$ containing 215, 258 and $349 \mathrm{~g} \mathrm{WSC} / \mathrm{kg}$ DM respectively, of which 164, 179 and $185 \mathrm{~g} / \mathrm{kg} \mathrm{DM}$ was fructan were harvested onto ice, chopped to $1 \mathrm{~cm}$ lengths and fermented in vitro at $39^{\circ} \mathrm{C}$ under anaerobic conditions with an equine faecal inoculum. The evolution of head-space gas was used as an indirect measurement of fermentation and was monitored for $72 \mathrm{~h}$. Rate and degradation parameters were determined by modeling gas production profiles.

\section{Results}

The fractional rate of gas production was significantly $(P<0.05)$ greater for $P$ than $C$ and $T, P$ being fermented at
Both the fractional rate (FRGP) and extent (DM loss) of fermentation were significantly greater for $P$ than $C$ and $T$ reflecting differences in the WSC contents of the three grass species. FRGP reflects the proportions of readily or poorly fermentable material within a substrate; substrates with high proportions of readily fermentable material have faster fractions of poorly fermentable material. P contained the highest proportion of readily fermentable WSC which was reflected in its rapid FRGP, whilst T had the lowest content of WSC and the slowest FRGP.

However, these results may not be entirely due to differences in WSC content. The WSC fraction of grass is composed of many different molecules of differing molecular weight. Fructan molecules exist in a series of increasing size, and the larger molecules may take longer to breakdown and ferment than those of smaller size. Thus, not only WSC content but also WSC composition may be responsible for the observed differences in fermentation kinetics between the 3 grass species. Indeed it is known that Timothy contains high molecular weight fructans and PRG fructans of much lower molecular mass, whilst those of cocksfoot are intermediate (Ince, 2003, unpublished data); these differences would certainly agree with the differences in fermentation rates reported here. However, more work is necessary to clarify whether fermentation rate relies on WSC content only or if it is also affected by the molecular mass of its constituent molecules. This could be achieved by pre-treating the grass by subjecting it to a simulated foregut digestion process which would remove the simple WSC sugars leaving the fructan fraction intact.

\section{Conclusions}

Of the three species investigated, T had the lowest WSC content, rate of fermentation and end-point DM disappearance. This suggests that, although $T$ had the lowest nutritive value in terms of DM digestibility, its slower fermentation rate means that, of the three species tested here, it may be the least likely to cause hindgut acidosis. tional rates of gas production than those with high propor- 


\section{References}

Longland A. C. and Cairns A. J. (2000): Fructans and their implication in the aetiology of laminitis. Proceedings of the 3rd International Conference on Feeding Horses, Scientific Session, 52-55

Longland A. C. and Murray J. M. D. (2003): Effect of two varieties of perennial ryegrass differing in fructan content on fermentation parameters in vitro when incubated in vitro with a pony faecal inoculum. Proceedings of the Eighteenth Equine Nutrition and Physiology Symposium, 144-145

\section{Fermentation of selected substrates in vitro using a batch culture with equine faeces as inoculum}

\author{
Annette Zeyner', Beate Bosch', Klaus D. Markuske', Manfred \\ Fuerll ${ }^{2}$ and Monika Krüger ${ }^{3}$
}

Institute of Animal Nutrition, Nutritional Diseases and Dietetics ${ }^{1}$, Large Animal Clinic for Internal Medicine ${ }^{2}$ and Institute of Bacteriology and Mycology ${ }^{3}$, University of Leipzig, Germany

\section{Introduction}

Composition and activity of the guts' microbiota contribute essentially to the health of the host. In horses this is impressive highlighted in case of feed-induced laminitis (Garner et al. 1975, Pollitt and van Eps 2002). Thus, the investigation of fermentative processes in the hind gut and particularly the caecum is of special interest, but in vivo and ex vivo in vitro highly complicated. Using faeces as inoculum for in vitro incubation may allow, at least on principle, to study the fermentation of substrates assumed that they enter the terminal gut (McDaniel et al. 1993, Zeyner 2002, Longland and Murray 2003, Moore-Colyer et al. 2003, Murray et al. 2003, Ince et al. 2005, Lattimer et al. 2005, Vervuert et al. 2005). Fermentation characteristics as to dynamics and products may be helpful to value the protective or risk potential of substrates. Therefore, this investigation was conducted to characterise fermentation patterns of individual substrates rich in different carbohydrates (cellulose, pectin, starch, inulin, lactose, lactulose) incubated with equine faeces.

\section{Material and methods}

To incubate mixed faeces from two adult horses after four weeks of feeding a forage-based diet, a modified 'Hohenheim Gas Test' was used (Zeyner 2002). For this, 250 mg per syringe of cellulose $(\mathrm{CL}, 995 \mathrm{~g}$ cellulose $/ \mathrm{kg})$, citrus pectin (PC), Jerusalem artichoke meal (JA, $604 \mathrm{~g}$ inulin and $87 \mathrm{~g}$ disaccharides $/ \mathrm{kg}$ ), lactose (LA), lactulose syrup (LU, $503 \mathrm{~g}$ lactulose and $141 \mathrm{~g}$ other disaccharides $/ \mathrm{kg}$ ) and pre-gelati-
Nilsson U., Oste R., Kagerstad M. and Birkhead D. (1988): Cereal fructans: In vitro and in vivo studies in availability in rats and humans. Journal of Nutrition 1 18, 1325-1330

J. C. Ince

Institute of Grassland and Environmental Research

Plas Gogerddan

Aberystwyth, SY23 3EB, UK

Jennifer.ince@bbsrc.ac.uk

nised wheat starch (ST) were incubated, three times each. In parallel, substrate (SU) and inoculum (IO) alone were repeatedly incubated. The net gas production (NGP) was measured at hrs. $0,7,10,15$ and finally 24 of incubation. NGP per hour of the individual time frames of incubation was calculated. After incubation has been finished, the supernatant fluid from each syringe was extracted to measure the $\mathrm{pH}$, short chain fatty acids (SCFA: acetic acid, propionic acid, $\mathrm{n}$ - and iso-butyric acid, n-and iso-valeric acid, n-capronic acid) and ammonia as described by Zeyner et al. (2004), D- and L-lactate according to Noll (1966; modified by K. D. Markuske, unpublished data) and the total equivalent water-soluble antioxidant capacity (TEAC) by Miller et al. (1996). Faecal bacteria groups (total aerobes and anaerobes, Gram-negative aerobes, yeasts, lactobacilli, bifidobacteria, enterococci, C. perfringens) were investigated by cultural studies. SPSS 11.0 (SPSS Inc., Chicago, Illinois, USA) was used to analyse data by means of linear regression and analysis of variance with main factors 'substrate' and 'incubation time' (for NGP only). For post-hoc multiple comparison of means the SNK test was stressed. The level of statistical significance was pre-set at $p<0.05$.

\section{Results}

There were no substantial differences between counts of faecal bacteria of the two horses. C. perfringens were found to be below $10^{3}$ colony forming units/g. Because results were similar, data from all substrates incubated without faeces were summed up. With IO, SU and CL, NGP was not different from zero and the $\mathrm{pH}$ value was particularly high $(\mathrm{P}<0.05)$. LA and ST caused a rapid NGP during early incubation (Fig. 1). With PC, the final NGP was highly elevated. LU induced

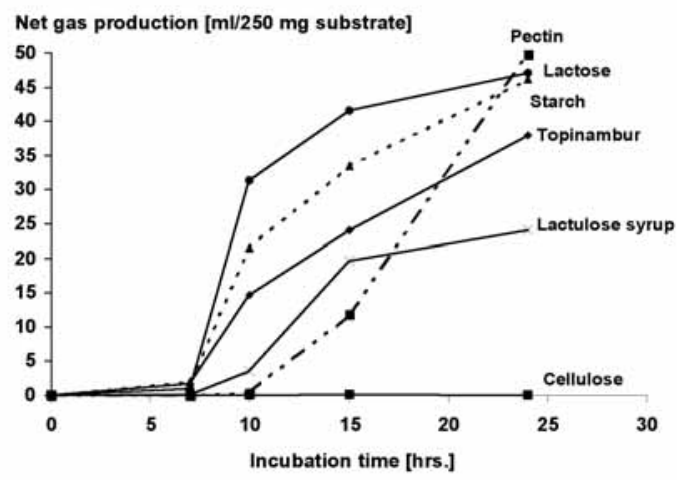

Fig 1 Net gas production (NGP) after incubation of different substrates with equine faeces. 
moderate fermentation patterns. $1 \mathrm{O}$, but not $\mathrm{SU}$, caused a measurable formation of SCFA, comparably to that with $\mathrm{CL}$. Highest SCFA ( $\mathrm{P}<0.05$; Fig. 2$)$ and lowest $\mathrm{pH}(\mathrm{P}<0.05)$ were measured with PC, JA, LA and ST. The acetate- propio-

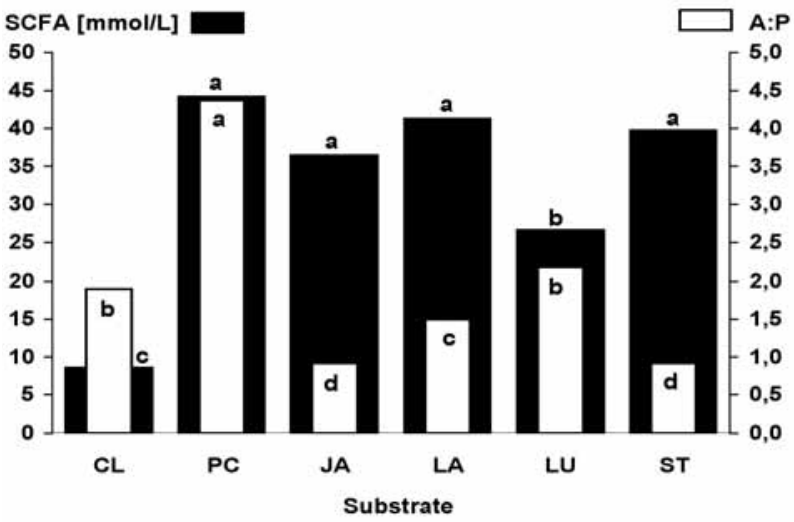

Fig 2 Short chain fatty acids (SCFA) and acetate-propionate quotient $(A: P)$ in the supernatant after incubation of different substrates with equine faeces.

nate quotient $(A: P)$ was especially elevated with $P C(P<0.05)$, moderate with LA $(P<0.05)$ and lowest with JA and ST $(P<$ 0.05; Fig. 2). With $L U$ and IO, pH was settled between $L A$ and $P C$. Between final SCFA and $\mathrm{pH}$ a close relation existed $(\mathrm{R}=$ $0.865, P<0.01)$. L- and D-lactate and their quotient were not different $(P>0.05)$ between substrates incubated with faeces. Ammonia was found to be highest $(P<0.05)$ with $C L$ and further higher $(P<0.05)$ with JA and $L U$ than with ST, LA and PC. TEAC after incubation of faeces alone and faeces plus any substrate was about 16-fold higher than with SU $(P<0.05)$.

\section{Discussion}

The different substrates used in this study caused highly individual fermentation characteristics as to process dynamics and products while incubated with equine faeces. For interpretations, the respective substrate must be regarded as a totality and it's individual effect can not be reduced to any interesting ingredient because other contained substances may have an additional effect. Different fermentation patterns (e.g. NGP, SCFA, pH, ammonia) interact physiologically plausible. In this way, PC, LA and ST caused especially high NGP and SCFA while $\mathrm{pH}$ and ammonia were particularly low. It can be speculated that nitrogen has extensively been incorporated into microbes. Because the environment was buffered within a relatively strict frame it had obviously not enough been acidified to promote lactic acid producing microbes as it is expected to be in vivo. Whether this may principally work in a batch culture system needs to be studied. A more sophisticated graduation of highly fermentable substrates was provided by NGP dynamics and SCFA patterns, e.g. A:P, indicating different proliferation rates of individual microbial species and thus substrate valuation regarding the gut's health. Most surprising was the finding that pure cellulose caused obviously a very few fermentative activity.

\section{Conclusions}

In vitro fermentation characteristics from a batch culture with equine faeces allows a sophisticated differentiation between substrates as to the potential stimulation of the microbiota and probable changes of the microbial community.

\section{References}

Garner H. E., Coffman J. R., Hahn A. W., Hutcheson D. P. and Tumbleson M. E. (1975): Equine laminitis of alimentary origi: an experimental model. American Journal of Veterinary Science 30, 44 1-444

Ince J., Longland A., Moore-Colyer M. and Harris P. (2005): Effect of inoculum source on fermentation parameters in vitro: incubation of perennial ryegrass (lolium perenne) varieties with microbial inocula from the cecum, right ventral colon or feces of ponies. Proceedings of the 19th Symposium of the Equine Science Society, May 31 -Jun 03, Tucson, USA, 303

Lattimer J. M., Cooper S. R., Freeman D. W. and Lalman D. A. (2005): Effects of Saccharomyces cerevisiae on in vitro fermentation of a high concentrate or high fiber diet in horses. Proceedings of the 19th Symposium of the Equine Science Society, May 31 Jun 03, Tucson, USA, 168-173

Longland A. C. and Murray J. M. D. (2003): Effect of two varieties of perennial ryegrass (lolium perenne) differing in fructan content on fermentation parameters in vitro when incubated in vitro with a pony faecal inoculum. Proceedings of the 18th Symposium of the Equine Nutrition and Physiology Society, May 04-07, East Lansing, USA, 144-145

McDaniel A. L., Martin S. A., McCann J. S. and Parks A. H. (1969). Effects of Aspergillus oryzae fermentation extract on in vitro equine cecal fermentation. Journal of Animal Science 71, 2164-2172

Miller N. J., Sampson J., Candeias L. P., Bramley P. M. and Rice-Evans C. A. (1996): Antioxidant activities of carotenes and xanthophylls. Federation of European Biochemical Societies Letters 384, 240-242

Moore-Colyer M. J. S., Longland A. C. and Murray J. (2003): Microbial activity and degradation capacity in nine regions of the equid gut using the gas production technique. Proceedings of the 18th Symposium of the Equine Nutrition and Physiology Society, May 04-07, East Lansing, USA, 1 18-120

Murray J. M. D., Longland A. C., Moore-Colyer M. J. S. and Dunnett C. (2003): The effect of diet and donor animal on the fermentative capacity of equine faecal inocula for use in in vitro digestibility determinations. Proceedings of the 18th Symposium of the Equine Nutrition and Physiology Society, May 04-07, East Lansing, USA, 121-123

Noll F. (1966): Methode zur quantitativen Bestimmung von L(+)-Lactat mittels Lactatdehydrogenase und Glutamat-Pyruvat-Transaminase. Biochemische Zeitschrift 346, 41 -49

Pollitt C. C. and Van Eps A. W.: Equine laminitis: A new induction model based on alimentary overload with fructan. Proceedings of the Australian Equine Veterinary Association. Bain-Fallon Memorial Lectures

Vervuert I., Coenen M. and Plumhoff S. (2005): In vitro fermentation patterns of different carbohydrates: Ranking of grass meal (cellulose), sugar beet pulp (pectin), oats (starch) and Jerusalem artichoke (fructans). Proceedings of the 19th Symposium of the Equine Science Society, May 31-Jun 03, Tucson, USA, 156-157

Zeyner A. (2002): Ernährungsphysiologische Wirkungen eines Austausches von stärkereichen Komponenten durch Sojaöl in der Reitpferdeernährung. Göttingen: Habilitation thesis

Zeyner A., Geißler C. and Dittrich A. (2004): Effects of hay intake and feeding sequence on variables in faeces and faecal water (dry matter, $\mathrm{pH}$ value, organic acids, ammonia, buffering capacity) of horses. Journal of Animal Physiology and Animal Nutrition 88, 7-19

\section{A. Zeyner}

Institute of Animal Nutrition, Nutritional Diseases and Dietetics University of Leipzig

Gustav-Kühn-Str. 8

04159 Leipzig

Germany

zeyner@vetmed.uni-leipzig.de 